\title{
ESTRATÉGIAS EXTENSIONISTAS DO CURSO DE ESPECIALIZAÇÃO EM EDUCAÇÃO AMBIENTAL DA UFSM
}

\author{
Marcelo Barcellos da Rosa ${ }^{1}$, Glaíse Bohrer Palma ${ }^{2}$ \\ 1 UFSM - marcelobdarosa@gmail.com \\ ${ }^{2}$ UNIFRA - Centro Universitário Franciscano - glaisepalma@yahoo.com.br
}

\section{RESUMO}

O curso de especialização em Educação Ambiental da Universidade Federal de Santa Maria completou 15 anos em 2010. São disponibilizados dois formatos distintos, presencial e à distância (EaD), onde são atendidos cinco pólos (cinco cidades do interior do RS) da Universidade Aberta do Brasil (UAB): Agudo, Cacequi, Panambi, São Sepé e Sapiranga. Este trabalho tem como objetivo apresentar algumas ações extensionistas envolvendo gestão informacional e de divulgação científica do curso, de modo a garantir uma maior visibilidade, tanto acadêmica, quanto social do mesmo. São propostas ações a organização bianual de um Congresso Internacional de Educação Ambiental (www.ufsm.br/panambi2011), com o objetivo de gerar discussões multi e interdisciplinares para que a sociedade tome providências na solução dos problemas ambientais, bem como, duas revistas eletrônicas de acesso gratuito e aberto, a Revista Eletrônica em Gestão,

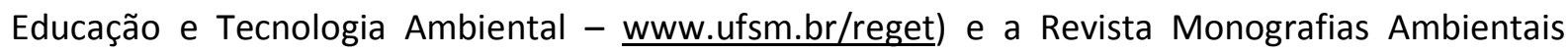
(www.ufsm.br/remoa), com o intuito de divulgar as pesquisas realizadas no âmbito do curso, bem como de disponibilizar a outras Instituições de Ensino Superior mais uma possibilidade de mostrar seus trabalhos nos mais diversos níveis acadêmicos, da graduação até resumos de teses de doutorado. Assim, as ações do curso em termos de divulgação científica e gestão informacional têm procurado atender as três temáticas básicas do curso, ou seja, a Educação, Sociedade $e$ Cultura; as Práticas Educativas Ambientais e a Discussão dos Problemas Ambientais.

Palavras-chave: educação ambiental, divulgação científica, gestão informacional 


\section{INTRODUÇÃO}

O curso de especialização em Educação Ambiental da Universidade Federal de Santa Maria, Santa Maria-RS está completando 16 anos de funcionamento em 2011. Este se caracteriza por absorver profissionais das mais diversas áreas do conhecimento e egressos de inúmeras instituições de ensino superior, públicas e privadas, de todo o Brasil.

O curso foi idealizado para atender três linhas temáticas, que refletem as linhas de pesquisa do curso, ou seja: Educação, Sociedade e Cultura, Problemas Ambientais e Práticas Educativas Ambientais.

Com o passar dos anos, concluiu-se que apenas a realização de palestras, seminários, colóquios e/ou workshops no âmbito acadêmico acabava por não ecoar socialmente todo o esforço coletivo por parte do corpo docente do curso na realização de projetos à luz da educação ambiental com um viés extensionista. Portanto, três ações estratégicas foram discutidas e colocadas em prática de modo a se tentar um maior alcance, tanto acadêmico, quanto social, de toda a pesquisa realizada pelo curso. Assim, em 2009, foi realizada a primeira edição do Congresso Internacional de Educação Ambiental da UFSM-UAB - Pólo Panambi/RS, contando com a participação de cerca de 550 participantes e vários trabalhos publicados.

Em novembro de 2010 foram lançadas duas revistas eletrônicas, a Revista Eletrônica em Gestão, Educação e Tecnologia Ambiental (REGET) e a Revista Monografias Ambientais (REMOA) que procuram servir como suporte digital para todas as pesquisas realizadas pelo especializandos, tanto no formato presencial, quanto à distância (EaD).

\section{METODOLOGIA}

As ações estratégicas (extensionistas) do Curso de Especialização em Educação Ambiental consistem em três: promover o Congresso Internacional em Educação Ambiental e criação de duas revistas eletrônicas, REMOA e REGET.

Na sequência são apresentadas as principais características metodológicas de cada ação. 
REGETHFSM

Rev. Elet. em Gestão, Educação e Tecnologia Ambiental

(e-ISSN: 2236-1170)

\section{Congresso Internacional de Educação Ambiental - UFSM-UAB - Pólo Panambi}

De 26 - 28 de novembro de 2009 foi realizado em Panambi, RS, a 1a edição do Congresso Internacional de Educação Ambiental UAB (Universidade Aberta do Brasil)/UFSM - Pólo Panambi, onde a organização do evento foi feita pelos docentes do Curso de Especialização em Educação Ambiental da UFSM, bem como pelos integrantes do Pólo UAB - Panambi.

A temática principal do I congresso foi "trabalhar saberes para a sustentabilidade" e contou com 550 participantes, 380 inscritos, representantes de 35 municípios, 8 estados da federação, divididos em três dias de evento. Na primeira edição ocorreram 3 palestras, 1 mesa redonda, 4 minicursos, 3 defesas de monografias de especialização (Especialização em Educação Ambiental da UFSM), 52 apresentações orais e realização de uma trilha ecológica.

A 2a edição do Congresso Internacional de Educação Ambiental, no âmbito da parceria com a Universidade Aberta de Brasil (UAB- Pólo Panambi), divulgou projetos do Curso de especialização em Educação Ambiental da UFSM, para que sirvam de modelo a outras instituições de ensino, prefeituras, indústrias visando a mitigação dos problemas ambientais.

Neste sentido, o congresso, além de divulgar as pesquisas de seus especializandos, apresentou uma série de palestras esclarecedoras envolvendo tanto a UAB, quanto o trabalho em Educação Ambiental a comunidade em geral e tendo como principal objetivo o desenvolvimento sustentável e melhoria de qualidade de vida das comunidades.

\section{Revista Eletrônica "Monografias Ambientais" - (REMOA - e-ISSN: 2236-1308)}

A Revista Eletrônica "Monografias Ambientais" ( $\underline{w w w . u f s m . b r / r e m o a}$ ) tem como objetivo atender a demanda de produção científica vinculada a todos os cursos/programas da UFSM e de outras instituições de ensino superior que trabalhem com a temática educação ambiental.

A missão da revista consiste em divulgar a produção científica gerada de pesquisas em nível graduação e pós-graduação que abordem a temática "educação ambiental" no contexto local, regional, nacional e internacional. Ela apresenta como público alvo a comunidade acadêmica nos seus diversos níveis (graduação, especialização, mestrado e doutorado). Quanto a sua política de submissão, são aceitos trabalhos gerados a partir de trabalhos de conclusão de curso, projetos 


\section{REGETAFSM}

Rev. Elet. em Gestão, Educação e Tecnologia Ambiental

(e-ISSN: 2236-1170)

de iniciação científica, monografias de pós-graduação, dissertações de mestrado e teses de doutorado que tenham como escopo, ou linha temática a educação ambiental. A REMOA oferece acesso livre imediato ao seu conteúdo, seguindo o princípio de que disponibilizar gratuitamente o conhecimento científico ao público proporciona maior democratização mundial do conhecimento.

\section{Rev. Eletrôn. em Gestão, Educ. e Tecnol. Ambiental (REGET - e-ISSN:2236-1170)}

A Revista em Gestão, Educação e Tecnologia Ambiental (www.ufsm.br/reget) tem como objetivo divulgar trabalhos científicos em nível de graduação e pós-graduação (Latu e Stricto Sensu) inseridos nas linhas temáticas de Gestão, Educação e Tecnologia Ambiental. Além disso, disponibilizar eletronicamente artigos científicos vinculados ao ensino, pesquisa e extensão que se enquadrem nas três linhas temáticas propostas. É uma publicação com periodicidade quadrimestral, compreendendo um volume por ano com três números. A Revista publica artigos originais, revisões, atualizações, estudos de casos e/ou relatos de experiências, resenhas, e resumos de teses e dissertações em Gestão, Educação e Tecnologia Ambiental com especial ênfase em originalidade e relevância científica.

Em relação ao processo de avaliação por pares, são aceitos artigos originais, destinados exclusivamente à REGET que contribuam para o crescimento e desenvolvimento da produção científica voltada a Tecnologia, Gestão e Educação Ambiental e áreas correlatas. São aceitos trabalhos em português, espanhol e inglês. As opiniões e conceitos emitidos pelos autores são de exclusiva responsabilidade dos autores, não refletindo, necessariamente, a opinião do Conselho Editorial da Revista.

A REGET tem periodicidade quadrimestral e o formato disponível é o meio eletrônico somente. Além disso, oferece acesso livre imediato ao seu conteúdo, seguindo o princípio de que disponibilizar gratuitamente o conhecimento científico ao público proporciona maior democratização mundial do conhecimento e utiliza também o sistema LOCKSS para criar um sistema de arquivo distribuído entre as bibliotecas participantes.

\section{RESULTADOS E DISCUSSÃO}

Em relação ao Congresso Internacional de Educação Ambiental: 
- atendeu a uma demanda de escolas estaduais e municipais da região, ou seja, os alunos participaram gratuitamente da programação do congresso;

- os professores da rede estadual e municipal puderam participar do congresso até como forma de vislumbrar novas práticas voltadas a inserção da educação ambiental no cotidiano educacional;

- atividades com empreendedores regionais, principalmente voltadas a Responsabilidade Social Corporativa (RSC), sustentabilidade, minimização de impacto ambiental, saúde e meio ambiente, entre outros temas, foram abordados;

- na segunda edição do congresso, em 2011, atendeu-se também o público da terceira idade através de atividades educativas envolvendo práticas ambientais no cotidiano;

- todos os trabalhos submetidos na forma de resumos serão publicados na modalidade de trabalhos completos na REMOA (edição de dezembro de 2011). Ou seja, dar-se-á visibilidade ao congresso na forma de publicação de artigos completos a todos os interessados que submeteram seus trabalhos.

Portanto, o alcance social e uma programação mais pluralizada são alguns dos aprimoramentos da 2 a edição do congresso, o que remete a um comprometimento ainda maior, tanto por parte da comissão organizadora local (Pólo UAB- Panambi), quanto da comissão da UFSM.

Em relação às revistas eletrônicas:

O envolvimento em termos de divulgação científica e gestão informacional da REGET e REMOA consistiu em:

- aprender/dominar o software SEER (Sistema Eletrônico de Editoração de Revistas);

- manter o site da revista atualizado com notícias, resumos de teses e novas edições;

- manter o fluxo de informações entre os autores e a gerência editorial de forma eficiente;

- colaborar na análise, revisão, ampliação e editoração de textos a serem publicados;

- participar ativamente do II Congresso Internacional de Educação Ambiental (setembbro 2011) na divulgação eletrônica de trabalhos completos no âmbito da parceria entre a REGET, REMOA e o Congresso; 
As ações expostas acima permeiam a tríade extensionista Comunicação, Educação e Meio Ambiente, onde a divulgação científica e tecnológica, a gestão informacional e as questões ambientais integram essas ações.

\section{CONCLUSÃO}

A divulgação de programas e ações críticas na área de Educação Ambiental é ponto de partida para qualquer projeto de sustentabilidade com responsabilidade social corporativa, conseqüentemente, extensionista. É desta forma que as ações propostas podem mostrar que uma educação a distância de qualidade atinge seus objetivos quando se tem resultados práticos que ajudam a comunidade a melhorar a qualidade de vida.

As ações extensionistas propostas neste trabalho visam divulgar os projetos do Curso de especialização em Educação Ambiental, para que sirvam de modelo a outras instituições de ensino, prefeituras, indústrias visando a diminuição dos problemas ambientais.

\section{REFERÊNCIAS}

$\underline{\text { www.ufsm.br/remoa }}$

$\underline{\text { www.ufsm.br/reget }}$

www.ufsm.br/panambi2011

$\underline{\text { www.ufsm.br/educacaoambiental }}$ 